Tropical Journal of Pharmaceutical Research March 2020; 19 (3): 525-532

ISSN: $1596-5996$ (print); 1596-9827 (electronic)

(C) Pharmacotherapy Group, Faculty of Pharmacy, University of Benin, Benin City, 300001 Nigeria.

Available online at http://www.tjpr.org

Original Research Article

http://dx.doi.org/10.4314/tjpr.v19i3.10

\title{
MicroRNA-421 protects against chronic intermittent hypoxia-induced vascular endothelial cell injury by targeting TLR4
}

\author{
Jie Yuan, Jiankuan Shi, Shuqi Yu, Hong Zhang* \\ The 1st Department of Neurology, Shaanxi Provincial People Hospital, Xian, Shanxi Province 701168, China
}

*For correspondence: Email: HongZhangguig@163.com; Tel: +86-02985251331-2372

Sent for review: 7 November 2019

Revised accepted: 24 February 2020

\begin{abstract}
Purpose: To investigate the role of miR-421 in endothelial cell injury caused by chronic intermittent hypoxia $(\mathrm{ClH})$, and to unravel the mechanism of action.

Methods: $A$ rat aortic endothelial cell model of $\mathrm{ClH}$ was established by 18-h exposure to hypoxic treatment. Cell viability was evaluated by MTT while cell apoptosis was determined by flow cytometry. Cellular reactive oxygen species (ROS) levels were assessed by cellular reactive oxygen species (ROS) assay kit. The mRNA and protein levels were also determined. Sprague Dawley rats were used to establish a rat $\mathrm{ClH}$ model over a 6-week hypoxic exposure. The degree of lung and renal injuries in the rats were observed by HE staining.

Results: MiR-421 was downregulated and toll-like receptor 4 (TLR4) upregulated in CIH cells compared to control cells. Treatment of CIH cells decreased their viability, increased cellular ROS levels, promoted cell apoptosis, and caused changes in protein levels of apoptosis- and inflammation-related genes. However, miR-421 mimics reversed these results caused by $\mathrm{ClH}$ treatment. Dual luciferase reporter assay verified that TLR4 was targeted by miR-421. Moreover, TLR4 overexpression suppressed the protective effect of miR-421 on CIH cells. Finally, miR-421 agomiR inhibited CIH-induced TLR4 upregulation in rats. Histopathological examinations confirmed that miR-421 agomiR inhibited $\mathrm{ClH}$ induced injury and collagen deposition in rat lungs and kidneys.

Conclusion: MiR-421 protects vascular endothelial cells against $\mathrm{ClH}$-induced injury in rats by targeting TLR4, which may provide a biomarker for the diagnosis and treatment of ClH-induced injury.
\end{abstract}

Keywords: Obstructive sleep apnea syndrome, MiR-421, TLR4, Chronic intermittent hypoxia, Vascular endothelial cells

\begin{abstract}
This is an Open Access article that uses a fund-ing model which does not charge readers or their institutions for access and distributed under the terms of the Creative Commons Attribution License (http://creativecommons.org/licenses/by/4.0) and the Budapest Open Access Initiative (http://www.budapestopenaccessinitiative.org/read), which permit unrestricted use, distribution, and reproduction in any medium, provided the original work is properly credited.
\end{abstract}

Tropical Journal of Pharmaceutical Research is indexed by Science Citation Index (SciSearch), Scopus, International Pharmaceutical Abstract, Chemical Abstracts, Embase, Index Copernicus, EBSCO, African Index Medicus, JournalSeek, Journal Citation Reports/Science Edition, Directory of Open Access Journals (DOAJ), African Journal Online, Bioline International, Open-J-Gate and Pharmacy Abstracts

\section{INTRODUCTION}

Obstructive sleep apnea syndrome (OSAS) is a common condition resulted from recurrent episodes of complete or partial obstruction in upper airway [1]. It may be caused by obesity, advanced age, male gender, alcohol abuse, and nasal obstruction [2]. It is well-known that OSAS can cause damage to multiple organs and systems, including the cardiovascular system, nervous system, lung, and kidney, [3-5]. Importantly, chronic intermittent hypoxia $(\mathrm{ClH})$ is 
a characteristic of OSAS [4] and a key factor of oxidative stress that induce the release of reactive oxygen species (ROS), which subsequently results in systemic inflammation [1]. Previous studies confirmed that $\mathrm{ClH}$ is responsible for the dysfunction and injury of endothelial cell $[6,7]$.

MicroRNAs (miRNAs) consist of about 22 nucleotides that can modulate the expression of target genes [7-9]. They play key roles in various diseases, such as cancers, diabetes, and cardiovascular diseases $[8,10,11]$. Many miRNAs are involved in the development of OSAS [5,12]. For example, miR-664a-3p expression is downregulated in OSAS patients [13]. It has also been reported that miR-630 may play important roles in OSAS-induced endothelial dysfunction [14]. The suppression of miR-30a inhibits $\mathrm{ClH}$ induced endothelial cell damage [6]. In particular, miR-421 plays key roles in various diseases such as cancer, epilepsy, and nonalcoholic fatty liver disease (NAFLD) [15-17]. Moreover, in human umbilical vein endothelial cells, it has been reported that miR-421 interacts with plasminogen activator inhibitor [18].

However, the relationship between miR-421 and $\mathrm{CIH}$-induced endothelial cell damage is unclear. Besides, previous reports demonstrated that TLR4 had important roles in the pathogenesis of $\mathrm{ClH}$-induced injury $[19,20]$. Thus, to determine whether miR-421 protects endothelial cells against $\mathrm{ClH}$-induced damage via targeting TLR4, a series of in vivo and in vitro experiments were performed.

\section{EXPERIMENTAL}

\section{Plasmid construction, miRNAs, and transfection}

The miR-421 mimics (miR-421), miR-NC, miR421-inhibitor, NC-inhibitor, miR-421 agomiR, and NC agomiR were from RiboBio (Guangzhou, China).

TLR4 cDNA was amplified (forward: 5'AGAAGAGCTGCAGCACCTGGATTT-3'; reverse:

GATGAAATTGGAATGAAGACCTCTCA-3') and cloned into the pcDNA3.1vector (Promega, Madison, WI, USA) to construct the TLR4 overexpression plasmid (pCDNA3.1-TLR4).

\section{Rat aortic endothelial cell model}

After synchronization, rat aortic endothelial cells were grouped as follows: control, $\mathrm{ClH}, \mathrm{ClH}+\mathrm{miR}$ $\mathrm{NC}, \mathrm{ClH}+\mathrm{miR}-421$ and ClH+miR-
421+pcDNA3.1-TLR4 group. Cells in control group were kept in serum-free culture under normoxic condition. In the $\mathrm{ClH}$ group, cells were treated with 21 to $1 \%$ of $\mathrm{O}_{2}$ every $15 \mathrm{~min}$ in a chamber (Proox C21, BioSpherix, Parish, NY, USA) for $18 \mathrm{~h}$. In the $\mathrm{ClH}+$ miR-NC, ClH+miR421 group, and $\mathrm{CIH}+\mathrm{miR}-421+\mathrm{pCDNA3} .1-\mathrm{TLR} 4$ groups, cells were co-transfected with miR-NC, miR-421 mimics, miR-421 mimics and plasmid pCDNA3.1-TLR4 by Lipofectamine 2000 (Invitrogen, Carlsbad, CA, USA). At 48 h, cells were harvested and exposed to $18-\mathrm{h} \mathrm{ClH}$ as described above.

\section{Animal model}

All experiments were conducted in accordance with the Guide for the Care and Use of Laboratory Animals of the Institutional Animal Care and Use Committees (IACUCs) of the United States [21] and approved by the institutional Animal Ethical and Welfare Committee (approval no. 2019-802).

Forty-five Sprague Dawley rats (male, 200 20 g; 6-week-old; from the Laboratory Animal Research Center of Fourth Military Medical University) were grouped as follows: sham, $\mathrm{ClH}+\mathrm{NC}$ agomiR, and $\mathrm{ClH}+\mathrm{miR}-421$ agomiR $(\mathrm{n}=15$ in each group). Rats in the $\mathrm{ClH}+\mathrm{NC}$ agomiR and $\mathrm{ClH}+\mathrm{miR}-421$ agomiR groups were kept in the chamber (Oxycycler model A84; BioSpherix) for 30 cycles/h for $8 \mathrm{~h}$ daily (from 9 am to $5 \mathrm{pm}$ ) for 6 weeks. In each 2-min cycle, oxygen concentration was dropped to $8 \%$ for $30 \mathrm{sec}$, maintained for $50 \mathrm{sec}$, and then increased to $20 \%$ for 40 sec. Sham rats were placed in the chamber with $20 \%$ oxygen throughout the experiment. Besides, rats in the $\mathrm{ClH}+\mathrm{NC}$ agomiR and $\mathrm{ClH}+\mathrm{miR}-421$ agomiR groups were injected through the tail vein with $\mathrm{NC}$ agomiR or $\mathrm{miR}-421$ agomiR at a concentration of $15 \mathrm{mg} / \mathrm{kg} /$ day twice a week. At week 6, blood was collected through cardiac puncture before euthanization. Lungs and kidneys were collected for further analysis.

\section{Cellular ROS assay}

Cellular ROS levels were assessed with a 2', 7'dichlorofluorescin diacetate cellular ROS detection assay kit (cat.no: ab113851, Abcam, Cambridge, UK).

\section{MTT assay}

Cells $\left(5 \times 10^{3}\right)$ were seeded into plates (12-well) and incubated $\left(2\right.$ days, $\left.37^{\circ} \mathrm{C}\right)$. Then, MTT (Sigma, St. Louis, MO, USA) was added and incubated $(4 \mathrm{~h})$. Next, the supernatant was replaced with dimethyl sulfoxide, and absorbance measured spectrophotometrically at $490 \mathrm{~nm}$. 


\section{Flow cytometry analysis}

Cells from different groups were washed with phosphate-buffered saline and then stained (Annexin V-fluorescein isothiocyanate and propidium iodide) for $10 \mathrm{~min}$. Apoptotic cells were examined using a flow cytometer (Beckman Coulter, Brea, CA, USA).

\section{Quantitative polymerase chain reaction (qPCR)}

The RNA from cells was extracted and cDNA was synthesized. qPCR was conducted with SYBR Green quantitative RT-PCR kits (Sigma). Relative expression levels were calculated as ratios normalized against those of GAPDH, using the following primer sequences:

TLR4 forward:

CCTTCGAGAAGCTCTCACGAC-3';

TLR4 reverse: 5'-CCGTTGGCGTAAAGGATGC3';

miR-421 forward:
TGGAAAACTTCCCGAAGAAC-3'; miR-421

GGGATCAACAGACATTAATT-3';

GAPDH forward:

TCATTGACCTCAACTACATGGTTT-3';

GAPDH reverse:

GAAGATGGTGATGGGATTTC-3'.

\section{reverse:5'- RESULTS}

5'-

\section{Dual luciferase reporter assay}

The 3'-UTR of TLR4 harboring wide-type or mutant putative miR-421 binding sites were amplified to construct TLR4 3'-UTR (WT) and TLR4 3'-UTR (MUT) plasmids. Cells were transfected with miR-421 mimics or miR-NC, and TLR4 3'-UTR (WT) or TLR4 3'-UTR (MUT) plasmid. Luciferase activities were measured at $48 \mathrm{~h}$.

\section{Histopathological examination}

Lungs and kidney tissue were fixed $(10 \%$ formalin) and embedded(paraffin). Hematoxylineosin (HE) or Masson staining was performed on $3-\mu \mathrm{m}$ serial sections. All sections were observed under an optical microscope.

\section{Western blot}

Proteins were extracted from cells and equal amount of protein were separated and transferred to nitrocellulose membranes. Then, membranes were incubated with primary antibodies (pro-caspase 3,1:500; pro-caspase 9, $1: 500$; cleaved-caspase $3,1: 400$; cleaved- caspase 9, 1:400; Bax, 1:200; Bcl-2, 1:400; interleukin (IL)-1及, 1:500; IL-6, 1:200;tumor necrosis factor (TNF)- $\alpha, 1: 200 ;$ TLR4, 1: 300; $\beta$ actin, 1: 200)for $16 \mathrm{~h}$ at $4^{\circ} \mathrm{C}$, including. After washing with TBST, blots were incubated with secondary antibodyat1:400for $1 \mathrm{~h}$. The antibodies were purchased from Abcam. Bands were visualized and analyzed.

\section{Enzyme-linked immunosorbent assay (ELISA)}

Cellular IL-1 $\beta$, IL-6, and TNF- $\alpha$ levels were detected using Rat ELISA Kits (ab100704, ab100713and ab108910, respectively; Abcam).

\section{Statistical analysis}

Data are presented as mean $\pm S D$, and each experiment consisted of at least three replicates per test. Differences between groups were assessed using one-way analysis of variance. The statistical significance threshold for all data was $p$ $<0.05$.

$\mathrm{CIH}$ treatment downregulated miR-421 and upregulated TLR4 in rat aortic endothelial cells

The viability of rat aortic endothelial cells was decreased in $\mathrm{CIH}$ group (Figure $1 \mathrm{~A}, p<0.05$ ). Figure 1B showed that $\mathrm{ClH}$ group had lower miR421 levels than control group $(p<0.001)$. However, the mRNA and protein expression of TLR4 were upregulated in $\mathrm{CIH}$ group (Figure 1C and $\mathrm{D}, p<0.01$ ).
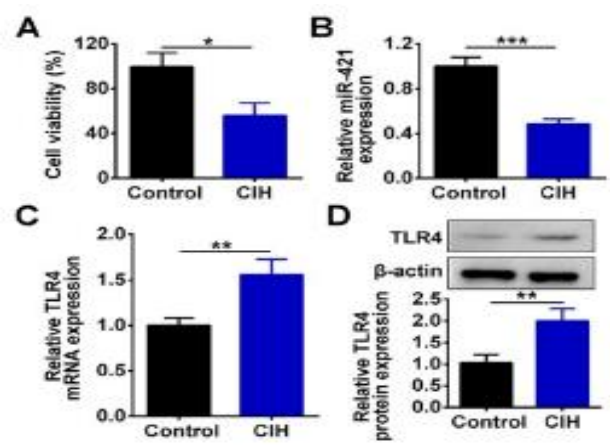

Figure 1: Effect of $\mathrm{ClH}$ treatment on the expressions of MiR-421 and TLR4 in rat aortic endothelial cells. (A) Cell viability was determined by MTT assay. The mRNA levels of miR-421 (B) and TLR4 (C) were evaluated by qPCR. D. TLR4 protein expression level was analyzed by western blot; ${ }^{*} p<0.05,{ }^{* *} p<0.01$, ${ }^{* \star *} p<0.001$ 
MiR-421 overexpression inhibited ClHinduced apoptosis and inflammation in rat aortic endothelial cells

Figure 2 A showed that miR-421 levels were decreased in $\mathrm{ClH}$ group $(p<0.01)$. However, miR-421 mimics reversed $\mathrm{ClH}$-induced downregulation of miR-421 (Figure $2 \mathrm{~A}, p<$ $0.001)$. The viability of rat aortic endothelial cells was decreased in the $\mathrm{CIH}$ group (Figure $2 \mathrm{~B}, p<$ 0.01 ). However, miR-421 mimics increased the reduction in cell viability caused by $\mathrm{ClH}$ treatment (Figure $2 \mathrm{~B}, p<0.05$ ). Moreover, $\mathrm{ClH}$ treatment significantly increased cellular ROS levels (Figure $2 \mathrm{C}, p<0.001$ ), whereas miR-421 mimics abolished this phenomena (Figure $2 \mathrm{C}, p$ $<0.01)$. Treatment of $\mathrm{ClH}$ also promoted cell apoptosis (Figure $2 \mathrm{D}, p<0.001$ ), and was suppressed by miR-421 mimics (Figure $2 \mathrm{D}, p<$ $0.05)$. In addition, the results showed that the protein levels of pro-caspase3, pro-caspase9, and $\mathrm{Bcl}-2$ were significantly decreased, whereas cleaved caspase 3 , cleaved caspase 9, Bax, IL$1 \beta$, IL-6, and TNF- $\alpha$ were significantly upregulated in $\mathrm{ClH}$ group (Figure $2 \mathrm{E}, p<0.001$ for cleaved caspase 9, Bax, IL-1 $\beta$, and Bcl-2; $p<0.01$ for other genes). In contrast, miR-421 mimics reversed $\mathrm{ClH}$-induced changes in protein levels of apoptosis- and inflammation-related factors (Figure $2 \mathrm{E}, p<0.01$ ). Besides, ELISA assay confirmed that miR-421 mimics significantly inhibited the $\mathrm{ClH}$-induced enhancement of inflammation factors (Figure $2 \mathrm{~F}$, $p<0.05$ for IL-6, and $p<0.01$ for IL- $1 \beta$ and TNF$\alpha)$.

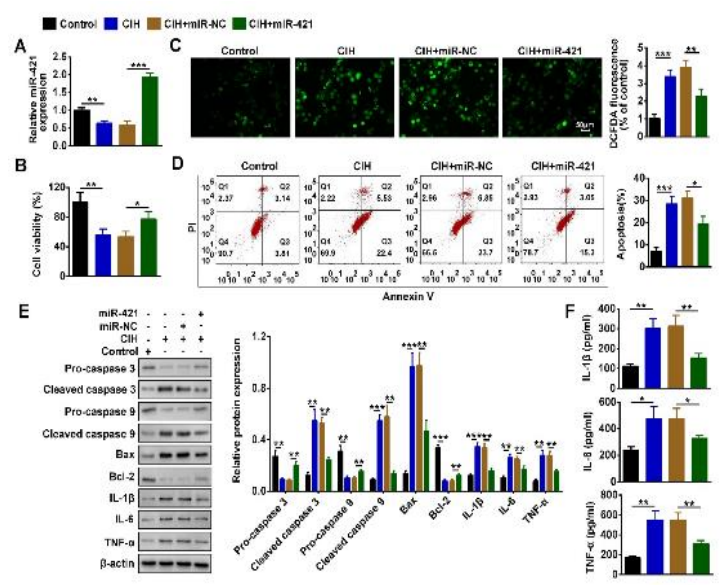

Figure 2: MiR-421 overexpression inhibited $\mathrm{ClH}$ induced apoptosis and inflammation in rat aortic endothelial cells A. qPCR assay of miR-421 level. B. MTT assay of cell viability. C. The measurement of cellular ROS levels. D. Flow cytometry assay of cell apoptosis. E. Western blot assay of protein levels. $F$. ELISA analysis of IL-1 $\beta, \mathrm{IL}-6$, and TNF- $\alpha$; ${ }^{*} p<0.05$, ${ }^{* *} p<0.01,{ }^{* * *} p<0.001$
Identification of TLR4 as a miR-421 target gene

TargetScan assay predicted that there were putative target sites of miR-421 in the TLR4 3'UTR (Figure $3 \mathrm{~A}$ ). Dual luciferase reporter assays showed that miR-421 mimics inhibited luciferase activity in cells harboring WT TLR4 3'UTR $(p<0.01)$, whereas had little effect on the luciferase activity of cells bearing MUT TLR4 3'UTR (Figure $3 \mathrm{~A}$ ). In rat aortic endothelial cells, miR-421 level was increased by transfection of miR-421 mimics group and was decreased by transfection of miR-421-inhibitor (Figure 3B, $p<$ 0.001). Besides, miR-421 mimics inhibited TLR4 mRNA (Fig $3 \mathrm{C}$ ) and protein expression (Figure 3 D) in endothelial cells $(p<0.01)$. However, miR421 inhibitor treatment promoted TLR4 mRNA (Figure $3 \mathrm{C}, p<0.05$ ) and protein (Figure $3 \mathrm{D}, p$ $<0.01$ ) expression.

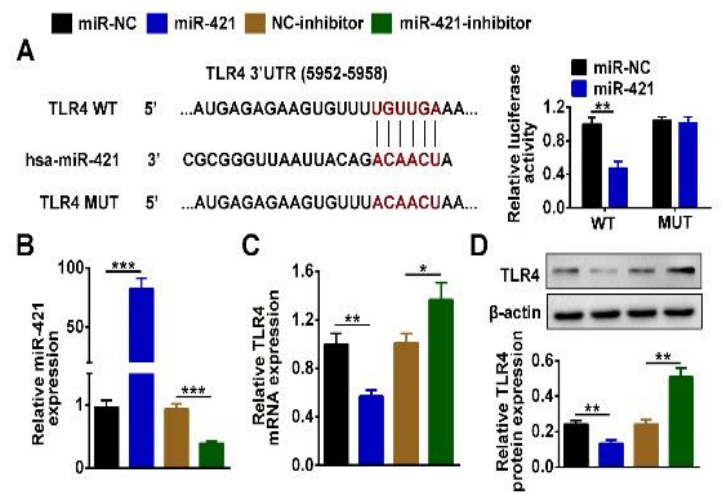

Figure 3: TLR4 was a target gene of miR-421 rat aortic endothelial cells A. Schematic diagram of miR421 binding sites in the TLR4 3'-UTR.Dual luciferase reporter assay was conducted $48 \mathrm{~h}$ after transfection. The relative expression levels of miR-421 (B) and TLR4 (C) were measured using qPCR. D. The relative TLR4 protein level was measured using western blot; ${ }^{*} p<0.05,{ }^{* *} p<0.01,{ }^{* *} p<0.001$

\section{TLR4 overexpression reversed the protective effects of miR-421 on rat aortic endothelial cells}

Figure $4 \mathrm{~A}$ shows that miR-421 mimics increased the viability of rat aortic endothelial cells under $\mathrm{ClH}$ stress compared to miR-NC $(p<0.05)$, whereas co-transfection of pcDNA3.1TLR4+miR-421 mimics reversed this result $(p<$ $0.01)$. Fig $4 \mathrm{~B}$ demonstrated that miR-421 mimics inhibited $\mathrm{ClH}$-induced increase in cellular ROS ( $p$ $<0.05$ ), whereas co-transfection of pcDNA3.1TLR4+miR-421 mimics reversed this result $(p<$ 0.01). Compared to miR-NC, miR-421 mimics inhibited cell apoptosis caused by $\mathrm{ClH}$ stress, whereas co-transfection of pcDNA3.1TLR4+miR-421 mimics suppressed the inhibitory 
effect of miR-421 mimics on cell apoptosis (Figure $4 \mathrm{C}, p<0.01$ ).

Western blotting revealed that miR-421 mimics downregulated TLR4 protein expression in $\mathrm{ClH}$ treated endothelial cells, whereas co-transfection of pcDNA3.1-TLR4 plasmid increased miR-421 mimics-induced downregulation of TLR4 (Figure $4 \mathrm{D}, p<0.001)$. Moreover, co-transfection of pcDNA3.1-TLR4 plasmid and miR-421 in $\mathrm{CIH}$ group reversed $\mathrm{miR}-421$ mimics-mediated increases in protein levels of pro-caspase 3 ( $p<$ $0.001)$, pro-caspase9 $(p<0.001)$, and Bcl-2 ( $p<$ 0.01 ) and the decreases in protein levels of cleaved caspase $3(p<0.01)$, cleaved caspase 9 $(p<0.01)$, Bax $(p<0.01), \mathrm{IL}-6(p<0.05)$, TNF- $\alpha$ $(p<0.05)$, and IL-1 $\beta(p<0.001$, Figure $4 \mathrm{D})$. ELISA assay confirmed that TLR4 overexpression inhibited the miR-421 mimicsmediated decrease in inflammatory factor levels (Figure $4 \mathrm{E}, p<0.01$ ).

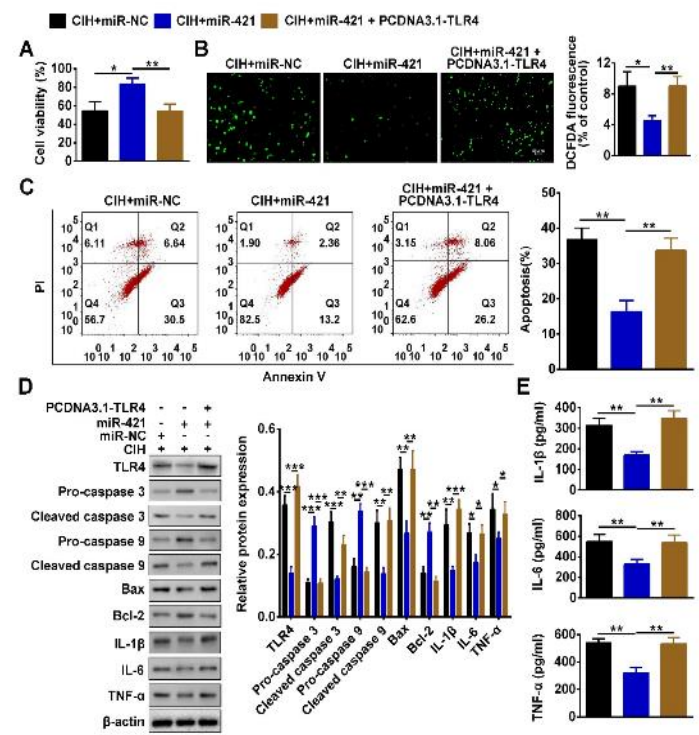

Figure 4: TLR4 overexpression reversed the protective effects of miR-421 in rat aortic endothelial cells A. Cell viability was detected by MTT assay. B. Cellular ROS levels were assessed by cellular ROS detection assay. C. Cell apoptosis was analyzed using flow cytometry. E. Protein expression levels were assessed by western blot. F. The levels of IL-1 $\beta$, IL- 6 , and TNF- $\alpha$ were measured by ELISA; ${ }^{*} p<0.05$; ${ }^{* *} p<0.01 ;{ }^{* *} p<0.001$

\section{MiR-421 inhibited $\mathrm{ClH}$-induced injury in rat lungs and kidneys}

As compared to the sham group, the miR-421 level in the $\mathrm{CIH}+\mathrm{NC}$ agomiR group was decreased to $51 \%$ (Figure $5 \mathrm{~A}, p<0.01$ ), whereas miR-421 level in $\mathrm{ClH}+$ miR-421 agomiR group was increased as compared to $\mathrm{ClH}+\mathrm{NC}$
agomiR group (Figure $5 \mathrm{~A}, p<0.001$ ). Rats in the $\mathrm{ClH}+\mathrm{NC}$ agomiR group had higher mRNA and protein levels of TLR4 than sham group (Figure 5B and C, $p<0.001$ and $p<0.01$ ). However, rats in the $\mathrm{ClH}+\mathrm{miR}-421$ agomiR group had lower levels of TLR4 mRNA and protein than $\mathrm{ClH}+\mathrm{NC}$ agomiR group (Figures $5 \mathrm{~B}$ and $\mathrm{C}, p<$ 0.001 and $p<0.05$, respectively). HE staining showed that the degree of lung injury and renal injury in the $\mathrm{CIH}+\mathrm{NC}$ agomiR group was higher than sham group, whereas miR-421 agomiR injection ameliorated $\mathrm{ClH}$-induced lung and renal injury (Figure 5 D). Importantly, miR-421 agomiR attenuated $\mathrm{ClH}$-induced collagen deposition in lung and renal tissues (Figures $5 \mathrm{D}$ and $\mathrm{E}$ ).

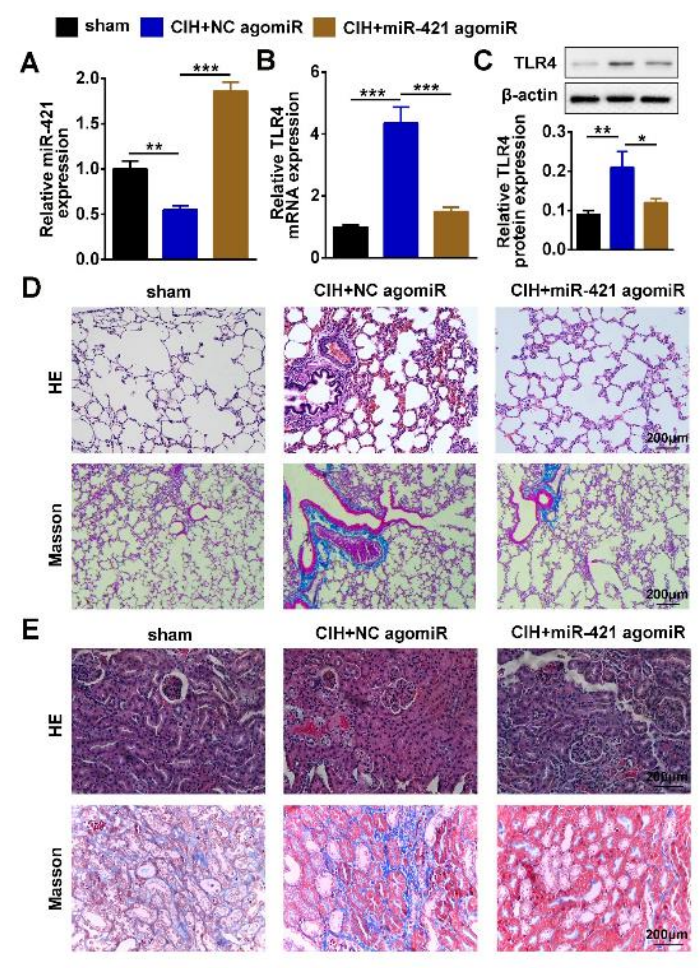

Figure 5: MiR-421 inhibited $\mathrm{ClH}$-induced injury in rat lungs and kidneys. A. Relative miR-421 levels in serum as analyzed using PCR. B-C. Relative TLR4 mRNA (B) and protein (C) levels in serum were detected by qPCR and western blot. The assessments of lung (D) and renal (E) injury were conducted in H\&E- and Masson-stained sections; ${ }^{*} p<0.05,{ }^{* *} p<$ $0.01,{ }^{* \star *} p<0.001$

\section{DISCUSSION}

It is well accepted that OSAS is chronic respiratory disease that can induce $\mathrm{CIH}$, which may result in endothelial dysfunction and multiple organ damage $[3,4,6]$. Many miRNAs, such as miR-664a-3p, miR-630, and miR-30a, play important roles during the development of OSAS $[6,13,14]$. In this study, ClH-treated 
endothelial cells had lower viability and decreased miR-421 levels compared to control cells, suggesting that miR-421 may exert protective effects on $\mathrm{ClH}$-treated endothelial cells. To verify it, endothelial cells were transfected with miR-421 mimics and then subjected to $\mathrm{CIH}$. Oxidative stress can be stimulated by $\mathrm{ClH}$ to trigger systemic inflammation and endothelial dysfunction [1]. Therefore, cell viability, apoptosis ratio, ROS levels, protein expression levels of apoptosisand inflammation-related genes were assessed. Compared to control group, $\mathrm{ClH}$ treatment decreased cell viability, increased cellular ROS levels, promoted apoptosis, caused changes in the protein levels of apoptosis-related genes, and increased inflammatory factor levels. However, miR-421 mimics inhibited these $\mathrm{ClH}$-induced phenomena.

MiRNAs can inhibit transcript expression via complementary base pairing [7]. Previous studies have characterized several direct targets of miR421, including PDCD4 and caspase-10 in breast cancer [17,22], claudin-11 in gastric cancer [23], and sirtuin 3 in NAFLD [16]. In this study, TargetScan analysis and luciferase reporter analysis identified that TLR4 as a novel miR-421 target. MiR-421mimics suppressed TLR4 mRNA and protein expression in endothelial cells, whereas miR-421 inhibitor promoted TLR4 mRNA and protein expression. This is the first evidence showing that miR-421 targets the TLR4 3'-UTR and regulates the TLR4 expression in endothelial cells.

Toll-like receptor 4 (TLR4)is a type I transmembrane protein [24], and it has important roles in the development of $\mathrm{ClH}$-induced injury of various organs and systems[19,20,25-27]. For example, Yang et al found that TLR4 signaling contributed to $\mathrm{ClH}$-induced pulmonary inflammation [25]. Zeng and colleagues showed that TLR4 signaling promoted $\mathrm{ClH}$-induced atherosclerosis [26]. Zhang et al demonstrated that TLR4 deficiency attenuated $\mathrm{ClH}$-medicated renal dysfunction in mice [27].

Consistent with previous reports, TLR4 was upregulated in $\mathrm{ClH}$ cells compared to control cells in this study, which suggested that the protective effects of miR-421 on $\mathrm{ClH}$ cells may be associated with TLR4 upregulation. To test it, endothelial cells were transfected with miR-421 mimics and TLR4 overexpression plasmid. In vitro experiments showed that co-transfection of TLR4 overexpression plasmid suppressed the protective effects of miR-421on $\mathrm{ClH}$ cells. These results suggest that $\mathrm{miR}-421$ protected endothelial cells against $\mathrm{ClH}$-induced injury by targeting TLR4. Conversely, it is well-known that TLR4 may initiate inflammatory responses via at least two major signaling pathways, including myeloid differentiation factor 88 (MyD88)independent and -dependent pathways [24,25]. Further experiments are needed to further determine whether these two TLR4 signaling pathways is involved in the role of miR-421 in $\mathrm{CIH}$.

The rat $\mathrm{ClH}$ model was established by imitating the state of OSAS. Consistent with in vitro experiments, miR-421 overexpression inhibited TLR4 mRNA and protein expression in $\mathrm{CIH}$ mice compared to control. Moreover, histopathological analysis demonstrated that miR-421 overexpression attenuated $\mathrm{ClH}$-induced damage to the rat lung and kidney.

Thus, miR-421 downregulation and TLR4 upregulation were closely associated with $\mathrm{ClH}$ induced vascular endothelial cells injury. Moreover, miR-421 had protective effects against $\mathrm{ClH}$-induced damage via targeting TLR4. Restoring the function of miR-421 may be a potential strategy for suppressing $\mathrm{ClH}$-induced damage. In addition, these results suggest that TLR4 may be a novel therapeutic target for OSAS.

\section{CONCLUSION}

The findings of this study prove that miR-421 downregulation and TLR4 upregulation are closely linked with $\mathrm{ClH}$-induced vascular endothelial cells injury. Moreover, miR-421 protects against $\mathrm{ClH}$-induced vascular endothelial cell injury by targeting TLR4.

\section{DECLARATIONS}

\section{Acknowledgement}

This work was supported by Shaanxi Province General Projects in the field of social development. (Grant no. 2017SF-264).

\section{Conflict of interest}

No conflict of interest is associated with this work.

\section{Contribution of authors}

We declare that this work was done by the authors named in this article and all liabilities pertaining to claims relating to the content of this article will be borne by the authors. JY and $\mathrm{HZ}$ conceived and designed the experiments, JKS 
analyzed and interpreted the results of the experiments, SQY performed the experiments.

\section{Open Access}

This is an Open Access article that uses a funding model which does not charge readers or their institutions for access and distributed under the terms of the Creative Commons Attribution License (http://creativecommons.org/licenses/by/ 4.0) and the Budapest Open Access Initiative (http://www.budapestopenaccessinitiative.org/rea d), which permit unrestricted use, distribution, and reproduction in any medium, provided the original work is properly credited.

\section{REFERENCES}

1. Toraldo DM, Den F, Deb M, Scoditti E. Obstructive sleep apnoea syndrome: a new paradigm by chronic nocturnal intermittent hypoxia and sleep disruption. Acta Otorhinolaryngol Ital 2015; 35(2): 69-74.

2. Archontogeorgis $K$, Nena E, Papanas N, Steiropoulos $P$. The role of vitamin $D$ in obstructive sleep apnoea syndrome. Breathe (Sheff) 2018; 14(3): 206-215.

3. Chuang LP, Lin SW, Lee LA, Chang $\mathrm{CH}$, Huang $\mathrm{HY}$, Hu HC, Kao KC, Hsieh MJ, Yang CT, Li HY et al. Elevated Serum Markers of Acute Kidney Injury in Patients With Obstructive Sleep Apnea. J Clin Sleep Med 2019; 15(2): 207-213.

4. Wohlrab P, Soto-Gonzales L, Benesch T, Winter MP, Lang IM, Markstaller K, Tretter V, Klein KU. Intermittent Hypoxia Activates Duration-Dependent Protective and Injurious Mechanisms in Mouse Lung Endothelial Cells. Front Physiol 2018; 9(1754.

5. Yang $X, N i u X, X i a o Y$, Lin $K$, Chen X. MiRNA expression profiles in healthy OSAHS and OSAHS with arterial hypertension: potential diagnostic and early warning markers. Respir Res 2018; 19(1): 194.

6. Bi R, Dai Y, Ma Z, Zhang S, Wang L, Lin Q. Endothelial cell autophagy in chronic intermittent hypoxia is impaired by miRNA-30a-mediated translational control of Beclin-1. J Cell Biochem 2019; 120(3): 4214-4224.

7. Liu KX, Chen GP, Lin PL, Huang JC, Lin X, Qi JC, Lin QC. Detection and analysis of apoptosis- and autophagy-related miRNAs of mouse vascular endothelial cells in chronic intermittent hypoxia model. Life Sci 2018; 193(194-199.

8. Liu KX, Chen Q, Chen GP, Huang JC, Huang JF, He XR, Lin T, Lin QC. Inhibition of microRNA-218 reduces HIF1alpha by targeting on Robo1 in mice aortic endothelial cells under intermittent hypoxia. Oncotarget 2017; 8(61): 104359-104366.

9. Diao $L, Y u H$, Wang $S$, Yu Q, Li H, L L, X L, H L, X Q. MicroRNA-187 inhibits pentylenetetrazol-induced neuronal apoptosis and alleviates development of epilepsy in epileptic rats by regulating SPRY1 expression. Trop J Pharm Res 2019; 18(9): 1823-1829
10. Cao X, Zhang C, Zhang X, Chen Y, Zhang H. MiR-145 negatively regulates TGFBR2 signaling responsible for sepsis-induced acute lung injury. Biomed Pharmacother 2019; 111(852-858.

11. Kaneto CM, Nascimento JS, Prado M, Mendonca LSO. Circulating miRNAs as biomarkers in cardiovascular diseases. Eur Rev Med Pharmacol Sci 2019; 23(5): 2234-2243.

12. Santamaria-Martos F, Benitez I, Zapater A, Giron C, Pinilla L, Fernandez-Real JM, Barbe F, Ortega FJ, Sanchez-de-la-Torre M. Identification and validation of circulating miRNAs as endogenous controls in obstructive sleep apnea. PLoS One 2019; 14(3): e0213622.

13. Adameova AD, Bhullar SK, Elimban V, Dhalla NS. Activation of $\beta$ 1-adrenoceptors may not be involved in arrhythmogenesis in ischemic heart disease. Rev Cardiovasc Med 2018; 19(3).

14. Khalyfa A, Kheirandish-Gozal L, Khalyfa AA, Philby MF, Alonso-Alvarez ML, Mohammadi M, Bhattacharjee R, Teran-Santos J, Huang L, Andrade $J$ et al. Circulating Plasma Extracellular Microvesicle MicroRNA Cargo and Endothelial Dysfunction in Children with Obstructive Sleep Apnea. Am J Respir Crit Care Med 2016; 194(9): 1116-1126.

15. Wen $X$, Han XR, Wang YJ, Wang S, Shen M, Zhang ZF, Fan SH, Shan $Q$, Wang $L$, Li MQ et al. MicroRNA-421 suppresses the apoptosis and autophagy of hippocampal neurons in epilepsy mice model by inhibition of the TLR/MYD88 pathway. J Cell Physiol 2018; 233(9): 7022-7034.

16. Cheng Y, Mai J, Hou T, Ping J. MicroRNA-421 induces hepatic mitochondrial dysfunction in non-alcoholic fatty liver disease mice by inhibiting sirtuin 3. Biochem Biophys Res Commun 2016; 474(1): 57-63.

17. Wang Y, Liu Z, Shen J. MicroRNA-421-targeted PDCD4 regulates breast cancer cell proliferation. Int $J$ Mol Med 2019; 43(1): 267-275.

18. Marchand A, Proust C, Morange PE, Lompre AM, Tregouet DA. miR-421 and miR-30c inhibit SERPINE 1 gene expression in human endothelial cells. PLoS One 2012; 7(8): e44532.

19. Akinnusi M, Jaoude $P$, Kufel $T$, El-Solh AA. Toll-like receptor activity in patients with obstructive sleep apnea. Sleep Breath 2013; 17(3): 1009-1016.

20. Zhang C, Dong H, Chen F, Wang Y, Ma J, Wang G. The HMGB1-RAGE/TLR-TNF-alpha signaling pathway may contribute to kidney injury induced by hypoxia. Exp Ther Med 2019; 17(1): 17-26.

21. Council NR. Guide for the Care and Use of Laboratory Animals: Eighth Edition. 2010; 327(3): 963-965.

22. Hu TB, Chen HS, Cao MQ, Guo FD, Cheng XY, Han ZB, Li MQ. MicroRNA-421 inhibits caspase-10 expression and promotes breast cancer progression. Neoplasma 2018; 65(1): 49-54.

23. Yang $P$, Zhang M, Liu X, Pu H. MicroRNA-421 promotes the proliferation and metastasis of gastric cancer cells

Trop J Pharm Res, March 2020; 19(3): 531 
by targeting claudin-11. Exp Ther Med 2017; 14(3): 2625-2632.

24. Vaure C, Liu Y. A comparative review of toll-like receptor 4 expression and functionality in different animal species. Front Immunol 2014; 5(316-316.

25. Yang JJ, Wang SJ, Gao X, Wang B, Dong YT, Bai Y, Chen Y, Gong JN, Huang YQ, An DD. Toll-Like Receptor 4 (TLR-4) Pathway Promotes Pulmonary Inflammation in Chronic Intermittent Hypoxia-Induced
Obstructive Sleep Apnea. Med Sci Monit 2018; 24(71527161.

26. Zeng $X$, Guo $R$, Dong $M$, Zheng J, Lin H, Lu H. Contribution of TLR4 signaling in intermittent hypoxiamediated atherosclerosis progression. I Transl Med 2018; 16(1): 106.

27. Zhang Y, Su X, Zou F, Xu T, Pan P, Hu C. Toll-like receptor-4 deficiency alleviates chronic intermittent hypoxia-induced renal injury, inflammation, and fibrosis. Sleep Breath 2018. 